\title{
Role of cognitive enhancement in schizophrenia
}

\author{
This article was published in the following Dove Press journal: \\ Neuroscience and Neuroeconomics \\ 15 May 2014 \\ Number of times this article has been viewed
}

\section{Cherrie Galletly}

Discipline of Psychiatry, School of Medicine, The University of Adelaide, Ramsay Health Care (SA) Mental Health Services, Northern Adelaide Local Health Network, Adelaide, SA, Australia
Correspondence: Cherrie Galletly The Adelaide Clinic, Suite 13, 33 Park Tce, Gilberton, SA 508I, Australia Tel +6182698144

Fax +6I 82694388

Email cherrie.galletly@adelaide.edu.au
Abstract: Schizophrenia is a severe and usually chronic psychiatric disorder characterized by dysfunction in many domains. Hallucinations, delusions, and behavioral disturbances are prominent symptoms of the illness, and are appropriately a focus for treatment, but less attention is given to the cognitive deficits that are also typically found in schizophrenia. Whilst impairments in learning, memory, and executive function have been recognized for many decades, deficits in more subtle aspects of cognition have been recognized more recently. These include biases in the evaluation of information and difficulties with emotional and social cognition. Cognitive deficits make a substantial contribution to real-world function, and improving cognition has the potential to improve social and vocational outcomes. This review provides an overview of potential treatments for cognitive deficits in schizophrenia, including medications, psychological therapies, and neurostimulation. Despite optimal medication and case management, many people with schizophrenia do not achieve full remission. There is sufficient evidence to encourage widespread adoption of at least some of the current cognitive enhancement strategies. However, individual patients differ in terms of their symptoms, patterns of cognitive dysfunction, medication response, and social and occupational situations. Considerable work is therefore needed to personalize cognitive remediation to maximize the benefits. However, at present, these methods are underutilized, even when applied in a universal manner where all subjects receive the same treatment. The barriers to wider availability of these treatments are discussed.

Keywords: schizophrenia, psychosis, cognition, treatment, remediation

\section{Introduction}

The incidence of schizophrenia averages 15 per 100,000 annually, with a point prevalence of about 4.5 per 1,000 population. The average individual lifetime risk is $0.7 \%{ }^{1}$ Numerous factors contributing to its etiology have been identified. Inheritance of the disease has been solidly demonstrated, but rather than a single gene, or a small number of genes, many genes each with a very small effect have been identified. Events before birth have been implicated, including intrauterine starvation, exposure to influenza epidemics during the second trimester, obstetric complications, and perinatal infections. Children who later develop schizophrenia sometimes have soft neurological signs such as poor coordination, and their achievement at school tends to fall behind that of their siblings. Childhood adversity, including bullying, neglect, and abuse, increases the risk of later schizophrenia. Further, migration, especially where the migrant is part of a visible minority community, is also associated with an increased risk of schizophrenia. One unifying theory is that "social defeat", ie, being subject to 
racism or discrimination, plays a part in increasing vulnerability to psychotic disorders such as schizophrenia. ${ }^{2}$

The "two-hit" hypothesis proposes that against this background vulnerability, further events can precipitate the first episode of psychosis. There is most evidence for the contribution of cannabis abuse, especially if the person starts using this at an early age. ${ }^{3}$ Other drugs, such as stimulants, and psychosocial stressors are also thought to act as precipitants of the first psychotic episode.

People with psychosis often describe an extraordinary sense of meaning attached to everyday events. Animal studies have shown that dopamine neurons are activated by unexpected personally significant events. It has been proposed that dysfunction of the dopamine system, such that abnormal salience is attached to mundane events, is responsible for the development of delusional beliefs, and that schizophrenia is fundamentally a salience dysregulation syndrome. ${ }^{4}$

Whilst overactivity in the mesolimbic dopamine tracts is thought to be responsible for the positive symptoms of schizophrenia, reduced activity in the mesocortical dopamine tracts is associated with the negative and cognitive symptoms of schizophrenia. The catechol-O-methyltransferase Val(158) Met polymorphism is a common genetic variant known to affect prefrontal dopamine levels. The Val/Val genotype is associated with higher enzymatic activity, resulting in lower dopamine concentrations in the prefrontal cortex, along with poorer performance on cognitive tests, compared with the Met/Met genotype. A prospective study found that cannabisusing adolescents with the Val allele had a higher risk of developing psychosis than those with the Met/Met genotype, ${ }^{5}$ but a recent meta-analysis concluded that, overall, catecholO-methyltransferase polymorphisms are not associated with increased susceptibility to schizophrenia. ${ }^{6}$

All antipsychotic drugs have dopamine antagonist properties, which provides further support for a central role of dopamine in schizophrenia. However, whilst these drugs are often effective in reducing positive symptoms, they have less impact on negative symptoms and cognition, so the dopamine hypothesis clearly does not account for the full range of pathology in schizophrenia. Glutamate, acting at N-methyl-D-aspartate (NMDA) receptors, has an inhibitory action regulating dopamine neurotransmission. Hypofunction of NMDA receptors might therefore indirectly result in dopaminergic overactivity and positive symptoms. NMDA receptor antagonists such as ketamine and phencyclidine produce a psychosis with neurocognitive deficits similar to schizophrenia, but studies of the association between glutamate activity and specific neurocognitive measures have been inconclusive. ${ }^{7}$
This review describes the disability and costs associated with schizophrenia. Cognitive deficits appear to make a substantial contribution to the disability, which leads on to consideration of the causes of cognitive impairment and possible treatments. Finally, barriers to more widespread access to cognitive remediation are discussed.

\section{Costs of schizophrenia}

Despite its relatively low prevalence compared with disorders such as depression, schizophrenia is very costly. ${ }^{8}$ The onset is commonly in late adolescence or early adulthood, and whilst a proportion of people do eventually recover, lifelong disability is the usual outcome. In a recent Australian national survey of people living with psychotic illness (predominantly schizophrenia and related disorders), 85\% of participants were supported by government benefits. ${ }^{9}$ In addition, people with chronic mental illness often receive subsidized medications and utility bills, along with rental assistance or government housing.

People with schizophrenia generally suffer acute relapses, with incomplete recovery between episodes. Therefore, they often require hospitalization, and hospitals are the most expensive component of health services. Between episodes, various types of community care, such as case management or assertive community care, along with rehabilitation, are required.

Schizophrenia is associated with high rates of physical comorbidity. About $60 \%-70 \%$ of people with schizophrenia smoke (compared with about $25 \%$ of the general population) and this has obvious health implications. ${ }^{10}$ In addition, obesity, metabolic syndrome, and diabetes are more common in people with schizophrenia. The recent Australian national survey found that $41 \%$ of 1,825 adults with psychotic disorders had attended an emergency department in the previous 12 months, with $21 \%$ attending for physical health problems and $26 \%$ for acute psychiatric problems. ${ }^{11}$

Along with tobacco use, people with schizophrenia have higher rates of alcohol and substance abuse and dependence. The chronic abuse of these substances worsens both physical and mental health. In addition, after purchasing tobacco, drugs, and/or alcohol from a very limited income, there is little money left for items such as clothing and toiletries or recreational activities. ${ }^{12}$ The Australian national survey of people living with psychosis found that $28 \%$ of participants reported that at least once in the previous 12 months, they did not have enough money to buy food. ${ }^{11}$

There are also substantial indirect costs. Families bear a considerable burden of care and often lose work opportuni- 
ties because of their responsibilities to the family member with schizophrenia. Social participation is reduced for both the person with schizophrenia and their family, leading to nonfinancial losses for the community as a whole.

Many people with schizophrenia say they would like to work. However, employment rates are very low. ${ }^{13,14}$ It has been shown that a place-and-support model, where the person is placed into a job then supported to maintain that job, is more effective than providing the person with training and work skills then placing them in a job. ${ }^{15}$ Vocational rehabilitation services applying the place-and-support model should be widely available. In reality, most people with schizophrenia report that they are not getting the help they need to find work. Greater workforce participation would have obvious economic benefits, as well as improving quality of life.

\section{Cognitive impairment in schizophrenia}

Schizophrenia was described by Emil Kraeplin in 1893 as "dementia praecox", or precocious dementia, meaning that it was an illness that began at a relatively young age and was characterized by dementia, ie, impaired memory and cognition. These insights were later overshadowed by interest in "first rank" symptoms, eg, various types of hallucinations and delusions. About 20 years ago, there was a resurgence of interest in the cognitive deficits found in schizophrenia. One reason for this was that, at least superficially, people with schizophrenia were doing much better. Most were living in the community rather than in asylums, with support from mental health services. Mental health case management, community day programs, and rehabilitation programs were available for many patients. Novel atypical antipsychotic drugs were better tolerated than the older drugs, and generally did not have neurological side effects such as drug-induced Parkinsonism. Despite these improvements, very few people with schizophrenia were working. Researchers investigating the barriers to employment found that cognitive deficits were a better predictor of functioning than positive symptoms (hallucinations and delusions). Almost 15 years ago, Green et al ${ }^{16}$ reported that cognitive impairment accounted for $20 \%-60 \%$ of the variance in functional outcome in schizophrenia. This led to a substantial increase in research into both the nature and causes of cognitive deficits, as well as measures to improve cognition.

One of the difficulties for researchers was the lack of consistency in the choice of instruments used to measure cognition in schizophrenia. The investigators generally chose neuropsychological tests that were sensitive to the particular domains they were interested in, selecting from a large number of available tests. Most studies had quite small participant samples.
Therefore, comparison between studies was confounded by the different methods of measurement, which made conducting reviews and meta-analyses difficult.

To address this problem, the National Institute of Mental Health established the Measurement and Treatment Research to Improve Cognition in Schizophrenia (MATRICS) project. This project brought together experts from diverse backgrounds to develop a standardized battery of cognitive tests that covered the domains typically affected in schizophrenia, and could be used to assess improvement in clinical trials. A consensus neuropsychological battery of ten tests was developed. ${ }^{17,18}$ This battery encompasses seven domains: speed of processing; attention/vigilance; working memory; verbal learning; visual learning; reasoning and problem-solving; and social cognition. ${ }^{18}$ Normative data for the MATRICS test battery have been obtained for 300 adults. ${ }^{19}$ The MATRICS test battery is now widely used and has allowed some standardization and comparison between studies. However, it has mostly been adopted for trials of cognitive-enhancing medications and is not so widely used in studies of other forms of cognitive remediation. Further, the MATRICS does not measure real-world function, which is perhaps better addressed by assessment tools that require the subject to undertake tasks such as planning an outing, following a recipe, or changing an appointment time. ${ }^{20}$

\section{Nature of the cognitive deficits}

One of the earliest studies in this field was undertaken by Saykin et al in 1994. ${ }^{21}$ They attempted to control for the possible negative effects of medication by comparing firstepisode (never medicated) and previously treated (currently unmedicated) subjects with schizophrenia. The two groups had nearly identical profiles, but the chronic group had more severe deficits. There was a pattern of generalized impairment, particularly in verbal memory and learning, attentionvigilance, and visual-motor processing and attention. The impairment was greatest on tests of verbal memory and learning. On average, the scores of the subjects with schizophrenia were about two standard deviations below those of the normal controls. Similarly, Bilder et $\mathrm{al}^{22}$ found that 94 subjects with first-episode schizophrenia had a generalized deficit on neuropsychological testing of approximately 1.5 standard deviations relative to a control group. Memory showed the greatest impairment, followed by executive and motor functions. Cognitive impairment is generally more profound and pervasive in schizophrenia compared with other psychotic disorders. ${ }^{23}$ 
Longitudinal studies have shown that people with schizophrenia have some cognitive impairment before the illness begins. This becomes more pronounced during the transition to psychosis and in the early years following diagnosis. Generally, the deficits remain stable in the later stages of the illness. ${ }^{24}$ According to the two-hit model, the earlier vulnerability is apparent as a reduction in cognitive function when compared with controls. At the time of the second "hit", through the prodromal period, there is a deterioration in cognition which parallels the brain changes seen at this time. ${ }^{25}$

\section{Potential confounds in measuring cognitive deficits in schizophrenia}

There are a number of difficulties in accurately measuring cognition in schizophrenia. People with schizophrenia often have negative symptoms, including poor energy, lack of motivation, anhedonia, and blunted affect. A person with severe negative symptoms may well struggle to engage in neuropsychological testing. The testing is often quite lengthy, sometimes taking several hours, and lack of motivation and energy can affect test performance. In addition, depression is a common comorbid condition, with about a quarter of people with schizophrenia meeting criteria for major depressive disorder over their lifetime. ${ }^{26}$ Depression is itself associated with impaired cognitive function; indeed, diminished ability to think and concentrate are among the diagnostic criteria. ${ }^{27}$ A person with comorbid schizophrenia and depression may therefore have additional cognitive deficits not directly due to their schizophrenia.

There is increasing awareness of the high rates of trauma in people with schizophrenia. Exposure to adversity in childhood, including physical, sexual and emotional abuse, neglect, parental death, or bullying is associated with an almost three-fold increase in the risk of developing a psychotic illness. ${ }^{28}$ Experience of the illness and its treatment can be traumatic. In addition, people with severe mental illness are a vulnerable population, and often subject to victimization. Post-traumatic stress disorder is associated with cognitive deficits, especially in working memory, so this can also be a factor contributing to poor performance on cognitive tests. ${ }^{29}$

Medication is another potential confounding factor. Many antipsychotic, antidepressant, and mood-stabilizing medications are sedating, which will impact on attention and speed of information processing. The high potency group of antipsychotic drugs can cause extrapyramidal (parkinsonian) side effects including tremor, rigidity and bradykinesia (slowing of movements). These side effects will reduce the ability to perform motor tasks, which are often part of neuropsychological test batteries. In addition, some antipsychotics and antidepressants have anticholinergic properties, which are associated with poorer performance on tests of memory. ${ }^{30}$

Drug and alcohol abuse or dependence are more common in people with schizophrenia than in the general population. In the Australian national survey of psychosis, half the sample were diagnosed with alcohol abuse/dependence (50.5\%) and/or cannabis abuse/dependence (50.8\%) ${ }^{11}$ Abuse of stimulants and other illicit drugs was also high, with over $70 \%$ of participants reporting lifetime use of these drugs. ${ }^{31}$ Both acute use (such as mild intoxication whilst undertaking testing) and chronic abuse of alcohol and cannabis are associated with cognitive impairment, and again these factors may aggravate poor cognitive function in people with schizophrenia.

Obesity (with an associated lack of exercise) and smoking are common in schizophrenia. The possibility that a proportion of people may suffer from sleep disorders, such as sleep apnea, has just started to receive attention. ${ }^{32}$ If these disorders are present, then they may contribute to daytime sedation. The finding that obesity is associated with poorer cognitive function in people with schizophrenia ${ }^{33}$ could perhaps be partly a result of sleep disorders, but of course there may be other explanations. In addition, elevated fasting glucose, impaired glucose tolerance, and insulin resistance are associated with poor cognitive performance and risk of developing cognitive impairment, and recent studies have shown that older people with diabetes have a higher risk of cognitive decline. ${ }^{34}$ People with schizophrenia tend to have abnormalities in glucose regulation and higher than normal rates of diabetes, ${ }^{35}$ so this may be another factor contributing to cognitive impairment.

\section{Educational achievement}

Schizophrenia is often preceded by a prodromal period, during which there is a gradual decline in function and onset of nonspecific subclinical symptoms. This most commonly occurs during adolescence and therefore disrupts education. On average, people with schizophrenia have lower education achievement, and are less likely to attend tertiary institutions or undertake trade training. This relatively lower educational level needs to be taken into account when interpreting the results of neuropsychological testing. Researchers often utilize the National Adult Reading Test, ${ }^{36}$ a test of premorbid intelligence. This test is based on the assumption that verbal ability remains relatively unaffected despite the decline in cognitive ability that may follow the onset of illness and is 
used to retrospectively estimate intelligence quotient levels in people with psychotic disorders before they became ill.

\section{Social cognition}

In addition to the problems with cognitive domains such as memory, learning, concentration, and executive function, people with schizophrenia also have difficulty with more subtle aspects of social and emotional cognition. These difficulties are most likely responsible for the very severe problems with social interaction typically experienced by people with schizophrenia. Social engagement can be quite limited, and people with schizophrenia often live alone, with few friends and little engagement in community activities. Problems in understanding and reacting appropriately to social cues may contribute to this failure of social inclusion and participation.

Social cognition is an aspect of cognitive function that includes the ability to understand and manage social interactions. Several components of social cognition have been identified, including emotional intelligence, theory of mind, and attributional style. These are assessed using tasks such as identifying emotion in human faces, and inferring how people might feel in specific situations represented in cartoon pictures. Theory of mind refers to the ability to understand mental states (eg, beliefs, desires, feelings, intentions) in other people or oneself. As might be expected, deficits in social cognition have been demonstrated in people with schizophrenia. ${ }^{37,38}$ A meta-analysis by Fett et $\mathrm{al}^{39}$ showed that social cognition accounted for $23 \%$ of the variance in functional outcome in schizophrenia, identifying it as a target for remediation. Earlier in the course of illness, impaired social cognition may also be a risk factor for psychosis. ${ }^{40}$

\section{Cognitive biases}

It has been proposed that cognitive processes may play a part in the development and maintenance of delusions. The hypothesis is that delusions may arise from normal cognitive mechanisms attempting to explain abnormal perceptual experiences. ${ }^{41}$ According to this theory, when an individual experiences aberrant perceptions such as auditory hallucinations, they search for an explanation using normal reasoning processes, and this gives rise to delusional beliefs.

More recently, researchers have become increasingly interested in the possibility that cognitive biases may contribute to the onset and maintenance of delusions. This work concerns two aspects of cognition, ie, biases in social cognition and biases in cognitive reasoning. The biases described in people with delusions include: attribution biases, where individuals exhibit an externalizing bias for negative events, with an inclination to blame others, rather than the situation or chance; ${ }^{42}$ attention biases, in which individuals are selectively attentive toward threat-related stimuli; ${ }^{43}$ high need for closure, which is a bias toward seeking definite answers to avoid ambiguity but at the cost of accuracy; ${ }^{44}$ impaired theory of mind, which leads to biases in assessing the intentions of others; ${ }^{45}$ belief inflexibility, or a bias against disconfirming evidence; and hypersalience of evidence-hypothesis matches, where even weak matches between the available evidence and existing beliefs or hypotheses are enhanced. ${ }^{46}$

\section{Improving cognitive function in schizophrenia}

Over the last 20 years, enormous effort has been directed toward trying to find treatments for the cognitive deficits characteristic of schizophrenia. A number of approaches have been used, including evaluating the effects of the secondgeneration antipsychotic drugs and trials of drugs with the potential to enhance cognition.

Psychological interventions began with simple tuition in problem-solving and executive tasks. More sophisticated methods have since been developed, delivered either via individual work with a clinician or using computerized remediation programs. Combinations of cognitive remediation and vocational rehabilitation seem especially promising. Early research into the remediation of deficits in social cognition and addressing biases in reasoning has reported positive results, but the numbers are small and many studies lack adequate control data.

\section{Medications} Antipsychotics

Initially, the second-generation antipsychotics were thought to be associated with improvement in cognitive function. Keefe et $\mathrm{al}^{47}$ in a meta-analysis of 15 studies investigating the effects of second-generation antipsychotics on cognitive function found modest cognitive enhancement with these drugs. However, when the Clinical Antipsychotic Trials of Intervention Effectiveness study compared the effects of four second-generation drugs with those of perphenazine, a firstgeneration drug, on cognition, there were no significant differences between the drugs. ${ }^{48}$ The 18 -month follow-up data tended to favor perphenazine. These results suggested that perhaps the beneficial effects of the second-generation antipsychotics had been overstated. Subsequently, it has become apparent that practice effects may have made a substantial contribution to the positive results of the earlier studies. $^{49,50}$ 
An electrophysiological study examining the effects of clozapine on information processing found that treatment with clozapine was associated with improved working memory updating and executive processing, ${ }^{51}$ indicating that clozapine may have unique actions in this regard. However the risks and adverse effects of clozapine are such that it is only used in treatment-resistant patients. Clozapine has a high affinity for dopamine D4 receptors, leading to the hypothesis that D4 receptor antagonism might be responsible for the beneficial effects on cognition. Animal studies suggest that drugs acting on the D4 receptor can influence cognitive function, ${ }^{52}$ but a study of sonepiprazole, a selective D4 dopamine antagonist, in patients with schizophrenia yielded negative results. ${ }^{53}$ However, clozapine has a range of other actions, including effects on D2, 5-HT2, histaminic, and muscarinic receptors, so these properties may also be important in both its antipsychotic action and its apparent cognitive benefits.

\section{Cognitive-enhancing drugs}

Drugs that have been shown to improve cognition in dementia are an obvious starting point, and indeed there have been a number of studies evaluating the capacity of acetylcholinesterase inhibitors to improve cognition in schizophrenia. The results have been mixed, with negative trials of donepezil, ${ }^{54}$ rivastigmine, ${ }^{55}$ and galantamine. ${ }^{56}$ However, some studies do find benefit. ${ }^{57}$ A Cochrane review in $2011^{58}$ concluded that whilst research favored the use of acetylcholinesterase inhibitors in combination with antipsychotics, the evidence was weak. Despite their ready availability, these drugs are not widely prescribed in schizophrenia.

People with schizophrenia are about five times more likely than the general population to use tobacco. ${ }^{59}$ In addition, they tend to smoke more heavily than other smokers. People with schizophrenia generally have a reduction in the ability to ignore a repeated, irrelevant stimulus. This inability to screen out irrelevant environmental inputs is termed "impaired auditory sensory gating". Ingestion of nicotine normalizes the auditory sensory gating deficit, assisting people with schizophrenia to negotiate complex environments. ${ }^{60}$ Smoking is also associated with other procognitive effects in schizophrenia, but not in other psychiatric disorders. ${ }^{61}$

Auditory sensory gating is associated with the $\alpha 7$-nicotinic receptor gene. ${ }^{62}$ Drugs acting on $\alpha 7$-nicotinic receptors could therefore have the potential to improve cognition in schizophrenia. ${ }^{63}$ In support of this theory, administration of nicotine, via nicotine patches, ${ }^{64}$ nasal spray, ${ }^{65}$ or cigarette smoking, ${ }^{66}$ has been shown to improve performance on some neuropsychological tests, particularly tests of attention, in people with schizophrenia. However, advocating smoking to enhance cognition is impractical, given the serious health consequences of smoking. Delivery via other vehicles, such as patches, spray or lozenges is still associated with the risks of addiction and withdrawal syndromes. ${ }^{65,67}$ A partial agonist at the $\alpha 7$ receptor, DMXB-A, (3-(2,4dimethoxybenzylidene)-anabaseine), has been evaluated in schizophrenia but so far results in terms of cognition have been disappointing. ${ }^{68}$ Verenicline, an $\alpha 4 \beta 2$ nicotinic acetylcholine receptor partial agonist used to aid smoking cessation, does seem to have some potential in enhancing cognition, especially the increased cognitive impairment related to tobacco cessation. ${ }^{69}$

Modafinil and its isomer armodafinil are effective for daytime fatigue in people with narcolepsy or sleep disorders associated with shift work. It therefore seems possible that they might be useful in schizophrenia. Unfortunately, addition of modafinil to an antipsychotic regimen has not been found to have beneficial effects on either daytime sleepiness or cognitive function in patients with schizophrenia. ${ }^{70,71}$

Glycogen synthase kinase (GSK)-3 $\beta$ is an enzyme implicated in neurodevelopmental processes. A recent metaanalysis has shown that the TT genotype of a single-nucleotide polymorphism in GSK-3 $\beta$ (rs12630592) is associated with reduced GSK-3 $\beta$ messenger (m)RNA in the post-mortem prefrontal cortex, attenuated functional magnetic resonance imaging prefrontal activity, reduced prefrontal cortical thickness, and a diagnosis of schizophrenia. ${ }^{72}$ There is some evidence that GSK-3 $\beta$ inhibitors can improve the cognitive deficits associated with a range of different conditions. ${ }^{73}$ In addition, inhibition of GSK-3 $\beta$ attenuates the psychotomimetic effects of ketamine, which as noted above, is a drug that antagonizes NMDA receptor function, ${ }^{74}$ leading to the suggestion that GSK-3 $\beta$ inhibitors might have a beneficial effect in schizophrenia. However, definitive clinical trials have not yet been undertaken.

As described above, there is considerable interest in the glutamate system in schizophrenia. NMDA receptor activity can be modified by a range of drugs, including NMDA receptor coagonists, glycine transporters inhibitors, ampakines, metabotropic glutamate receptor 5 (mGluR5) agonists, NMDA receptor partial agonists, and memantine. These drugs have therefore been evaluated for their potential as both antipsychotic and procognitive agents, but as yet only ampakines appear to have cognitive benefits. ${ }^{75}$

Lin et $\mathrm{al}^{76}$ have recently reviewed current treatments for cognitive impairment in schizophrenia, including drugs that 
act on dopamine, glutamate metabolism, $\gamma$-aminobutyric acid and serotonin systems, and oxytocin. They conclude that these studies tend to be confounded by small sample sizes and limited generalizability. They also note the potential benefits of combining cognitive-enhancing medications with nonpharmacological cognitive remediation.

\section{Cognitive remediation therapy}

A number of other targets for drug development have been identified, but so far none of the drugs available have shown substantial benefit in clinical trials. ${ }^{77}$ This lack of progress in psychopharmacology has highlighted the need for effective nonpharmacological methods of cognitive remediation.

Cognitive remediation therapy (CRT) aims to improve cognitive processes, with the expectation that changes will be durable over a substantial follow-up period and translate into real-world benefit. ${ }^{78}$ Some of the earliest studies demonstrated that it was possible to teach people with schizophrenia to improve their performance on the Wisconsin Card Sorting Test. Simple strategies such as vocalization (speaking aloud whilst performing the task) have been shown to improve performance on complex tasks. ${ }^{79}$

There are two main methods of CRT available. One-on-one clinician-delivered CRT is very time-intensive and therefore expensive. Computerized CRT is much cheaper to administer and has the potential to benefit many more patients. ${ }^{80}$ Some studies use a combination of the two methods; for example, Royer et al ${ }^{81}$ describe using psychologist-assisted pencil and paper exercises along with a computerized training program.

It makes sense to provide opportunities for the person to utilize their improved cognitive skills, so that gains can be consolidated. McGurk et $\mathrm{al}^{80}$ found that a combination of CRT and vocational rehabilitation was associated with an increase in hours worked and job retention, and was more effective than vocational rehabilitation alone. A study comparing CRT alone, functional skills training alone, and CRT followed by functional skills training found that CRT was associated with improved cognitive function, and functional skills training improved social competence. Again, combined treatment was superior. ${ }^{82}$

McGurk et al, ${ }^{83}$ in a meta-analysis of cognitive remediation in schizophrenia, found that CRT resulted in significant improvements, with a mean effect size of 0.41 for global cognitive performance, 0.52 for verbal working memory, 0.41 for attention and vigilance, and 0.47 for reasoning and problemsolving. The effect sizes were smaller for less proximal outcome measures, 0.36 for improvement in psychosocial functioning, and 0.28 for symptomatic improvement. Many of the studies had only small numbers of subjects, and were restricted to comparisons between cognitive measures before and after CRT. McGurk et $\mathrm{al}^{83}$ noted that many of these studies lacked measures of psychosocial outcome, and did not report long-term follow-up. Wykes et $\mathrm{al}^{84}$ described a study using a cliniciandelivered CRT program in young people with schizophrenia. The program required 40 hours of individual work with each patient. Tasks were designed to improve information processing strategies and included components of remembering, complex planning, and problem-solving. Three cognitive outcome measures were selected, and comparisons between the CRT group and the control group found statistically significant improvement in only one of these measures, with no significant effect of CRT on symptom severity or social functioning. There is some controversy about whether such modest gains are worth the investment of time and expertise. ${ }^{85}$

\section{Cognitive adaptation training}

Simple strategies such as diaries, calendars, and systems to remember important information can be useful. Whilst these measures are obviously helpful to ensure appointments and other commitments are not missed, they can also be used to prompt activities such as showering and domestic tasks. Mobile phone reminders and medication administration aids can help with medication adherence. Cognitive adaptation training $^{86}$ is a structured program that utilizes these practical measures, providing external support to improve function.

\section{Social cognition therapy}

A number of social cognition remediation programs have been developed. Evaluations of these programs have been encouraging, especially in regards to improving emotional perception, and robust improvements in facial affect recognition have been reported. ${ }^{87}$ As with CRT, computerized social cognitive training programs have been developed. These programs have the advantages of being more widely available and less expensive, ${ }^{88}$ and do show promise in preliminary studies with small numbers of subjects. Computer-assisted CRT and social cognitive group exercises have been combined in a program called cognitive enhancement therapy, which again has been shown to be effective. ${ }^{89}$ However, as yet, these therapies have only been established and evaluated within research programs and have not been widely utilized in clinical services.

\section{Metacognitive training}

Metacognitive training aims to directly address the cognitive biases thought to underlie delusional beliefs. ${ }^{90}$ Metacognitive training is generally delivered in small groups 
with an educational format, and initial results have been promising. ${ }^{91}$

\section{Neurostimulation}

Neurostimulation treatments such as repetitive transcranial magnetic stimulation and transcranial direct current stimulation tend to be more widely used in depression but may also be useful for people with schizophrenia. ${ }^{92}$ These methods do not require an anesthetic, are safe, and are generally well accepted by patients. Repetitive transcranial magnetic stimulation has been available for longer than direct current stimulation, so there is a more solid body of research regarding this form of neurostimulation in schizophrenia. ${ }^{93}$ The focus has been on hallucinations ${ }^{94,95}$ and negative symptoms, ${ }^{96-98}$ but there is some suggestion that cognition can be improved. ${ }^{99}$ Transcranial direct current stimulation machines are cheaper and application is easier, so in the long-term, if this method of treatment is shown to be effective, this may be more widely adopted. Current studies include combining transcranial direct current stimulation with CRT. ${ }^{100}$ Other approaches, such as paired associative stimulation and theta-burst stimulation, are in their incipient stages in the study and treatment of schizophrenia, with promising early results. There is some suggestion that repetitive transcranial magnetic stimulation might reduce cravings for tobacco, and this may be promising for the many people with schizophrenia who smoke. ${ }^{101}$

\section{Conclusion}

The importance of cognitive impairment in schizophrenia, involving both neurocognition and social cognition, is well established. Results of clinical trials of medications aiming to enhance cognition have so far not produced a drug that has been demonstrated to be effective. Psychological strategies seem to be more promising, but research has yet to be translated into clinical practice. Clinical practice guidelines are equivocal about the role of cognitive remediation and other strategies (National Institute for Health and Care Excellence guidelines), ${ }^{102}$ calling for further large, well conducted trials. Neurostimulation treatments are exciting, but only very preliminary research is available thus far. Much more robust data from large well conducted trials are needed. These trials should evaluate combinations of treatment, given that there does appear to be potential synergy.

However, the results thus far do justify more widespread use of interventions that have evidence for efficacy, are reasonably low-cost, and do not have obvious adverse effects, such as computerized CRT. The lack of widespread adoption of these interventions in clinical services reflects a number of real-world factors. Clinicians may have an inability to move beyond the established paradigm of medications and various forms of case management and rehabilitation. In addition, whilst the costs are not great, mental health services generally have budgetary constraints. New pharmacological treatments are in general widely promoted by their manufacturers, whereas psychological treatments lack this level of promotion and clinician education. Psychological strategies to enhance cognition rely on the efforts of researchers to communicate their findings and advocate for the methods shown to be beneficial, but researchers do not have the marketing skills and resources of a large pharmaceutical company.

\section{Acknowledgment}

The author sincerely thanks Cassandra Burton for her assistance with preparation of the final version of the manuscript.

\section{Disclosure}

The author reports no conflicts of interest in this work.

\section{References}

1. Tandon R, Keshavan MS, Nasrallah HA. Schizophrenia, "just the facts" what we know in 2008. 2. Epidemiology and etiology. Schizophr Res. 2008;102(1-3):1-18.

2. Van Os J, Kenis G, Rutten BP. The environment and schizophrenia. Nature. 2010;468(7321):203-212.

3. Burns JK. Pathways from cannabis to psychosis: a review of the evidence. Front Psychiatry. 2013;4:128.

4. van Os J. A salience dysregulation syndrome. Br J Psychiatry. 2009;194(2):101-103.

5. Caspi A, Moffitt TE, Cannon M, et al. Moderation of the effect of adolescent-onset cannabis use on adult psychosis by a functional polymorphism in the catechol-O-methyltransferase gene: longitudinal evidence of a gene X environment interaction. Biol Psychiatry. 2005;57(10):1117-1127.

6. Okochi T, Ikeda M, Kishi T, et al. Meta-analysis of association between genetic variants in COMT and schizophrenia: an update. Schizophr Res. 2009;110(1-3):140-148.

7. Merritt K, McGuire P, Egerton A. Relationship between glutamate dysfunction and symptoms and cognitive function in psychosis. Front Psychiatry. 2013;4:151.

8. Kennedy JL, Altar CA, Taylor DL, Degitiar I, Hornberger JC. The social and economic burden of treatment-resistant schizophrenia: a systematic literature review. Int Clin Psychopharmacol. 2014;29(2):63-76.

9. Morgan VA, Waterreus A, Jablensky A. People living with psychotic illness in 2010: the second Australian national survey of psychosis. Aust N Z J Psychiatry. 2012;46(8):735-752.

10. Cooper J, Mancuso SG, Borland R, Slade T, Galletly C, Castle D. Tobacco smoking among people living with a psychotic illness: the second Australian Survey of Psychosis. Aust N Z J Psychiatry. 2012;46(9): 851-863.

11. Morgan VA, Waterreus A, Jablensky A, et al. People living with psychotic illness 2010: report on the second Australian national survey. Commonwealth of Australia; November 2011. Available from: https:// www.health.gov.au/internet/main/publishing.nsf/Content/mental-pubsp-psych10. Accessed February 13, 2014. 
12. Borras L, Mohr S, Boucherie M, Dupont-Willemin S, Ferrero F, Huguelet P. Patients with schizophrenia and their finances: how they spend their money. Soc Psychiatry Psychiatr Epidemiol. 2007;42(12): 977-983.

13. Greve J, Nielsen LH. Useful beautiful minds - an analysis of the relationship between schizophrenia and employment. J Health Econ. 2013;32(6):1066-1076.

14. Waghorn G, Saha S, Harvey C, et al. 'Earning and learning' in those with psychotic disorders: the second Australian national survey of psychosis. Aust N Z J Psychiatry. 2012;46(8):774-785.

15. Bond GR, Drake RE. Making the case for IPS supported employment. Adm Policy Ment Health. 2014;41(1):69-73.

16. Green MF, Kern RS, Braff DL, Mintz J. Neurocognitive deficits and functional outcome in schizophrenia: are we measuring the "right stuff"? Schizophr Bull. 2000;26(1):119-136.

17. Harvey PD, Cornblatt B. Pharmacological treatment of cognition in schizophrenia: an idea whose method has come. Am J Psychiatry. 2008;165(2):163-165.

18. Nuechterlein KH, Green MF, Kern RS, et al. The MATRICS Consensus Cognitive Battery, part 1: test selection, reliability, and validity. Am J Psychiatry. 2008;165(2):203-213.

19. Kern, RS, Nuechterlein KH, Green MF, et al. The MATRICS consensus cognitive battery, part 2: co-norming and standardization. Am J Psychiatry. 2008;165(2):214-220.

20. Green MF, Schooler NR, Kern RS, et al. Evaluation of functionally meaningful measures for clinical trials of cognition enhancement in schizophrenia. Am J Psychiatry. 2011;168(4):400-407.

21. Saykin AJ, Shtasel DL, Gur RE, et al. Neuropsychological deficits in neuroleptic naive patients with first-episode schizophrenia. Arch Gen Psychiatry. 1994;51(2):124-131.

22. Bilder RM, Goldman RS, Robinson D, et al. Neuropsychology of firstepisode schizophrenia: initial characterization and clinical correlates. Am J Psychiatry. 2000;157(4):549-559.

23. Zanelli J, Reichenberg A, Morgan K, et al. Specific and generalized neuropsychological deficits: a comparison of patients with various firstepisode psychosis presentations. Am J Psychiatry. 2010;167(1):78-85.

24. Lewandowski KE, Cohen BM, Ongur D. Evolution of neuropsychological dysfunction during the course of schizophrenia and bipolar disorder. Psychol Med. 2011;41(2):225-241.

25. Sun D, Phillips L, Velakoulis D, et al. Progressive brain structural changes mapped as psychosis develops in 'at risk' individuals. Schizophr Res. 2009;108(1-3):85-92.

26. Siris SG. Depression in schizophrenia: perspective in the era of "atypical" antipsychotic agents. Am J Psychiatry. 2000;157(9):1379-1389.

27. American Psychiatric Association. Diagnostic and Statistical Manual of Mental Disorders. 5th ed. Arlington, VA, USA: American Psychiatric Association; 2013.

28. Varese F, Smeets F, Drukker M, et al. Childhood adversities increase the risk of psychosis: a meta-analysis of patient-control, prospective- and cross-sectional cohort studies. Schizophr Bull. 2012;38(4):661-671.

29. Honzel N, Justus T, Swick D. Posttraumatic stress disorder is associated with limited executive resources in a working memory task. Cogn Affect Behav Neurosci. October 29, 2013. [Epub ahead of print.]

30. Ogino S, Miyamoto S, Miyake N, Yamaguchi N. Benefits and limits of anticholinergic use in schizophrenia: focusing on its effect on cognitive function. Psychiatry Clin Neurosci. 2014;68(1):37-49.

31. Moore E, Mancuso SG, Slade T, Galletly CA, Castle DJ. The impact of alcohol and illicit drugs on people with psychosis: The second Australian national survey on psychosis. Aust $N Z J$ Psychiatry. 2012;46(9):864-878.

32. Kalucy MJ, Grunstein R, Lambert T, Glozier N. Obstructive sleep apnoea and schizophrenia - a research agenda. Sleep Med Rev. 2013;17(5):357-365.

33. Guo X, Zhang Z, Wei Q, Lv H, Wu R, Zhao J. The relationship between obesity and neurocognitive function in Chinese patients with schizophrenia. BMC Psychiatry. 2013;13:109.
34. Dragovic M, Waters FA, Jablensky A. Estimating premorbid intelligence in schizophrenia patients: demographically based approach. Aust NZJ Psychiatry. 2008;42(9):814-818.

35. Dash SK. Cognitive impairment and diabetes. Recent Pat Endocr Metab Immune Drug Discov. 2013;7(2):155-165.

36. Foley DL, Mackinnon A, Morgan VA, et al. Predictors of type 2 diabetes in a nationally representative sample of adults with psychosis. World Psychiatry. In press 2014.

37. Van Hooren S, Versmissen D, Janssen I, et al. Social cognition and neurocognition as independent domains in psychosis. Schizophr Res. 2008;103(1-3):257-265.

38. Stratta P, Bustini M, Daneluzzo E, Riccardi I, D’Arcangelo M, Rossi A. Deconstructing theory of mind in schizophrenia. Psychiatry Res. 201;190(1):32-36

39. Fett AJ, Viechtbauer W, Dominguez M, Penn DL, van Os J, Krabbendam L. The relationship between neurocognition and social cognition with functional outcomes in schizophrenia: a meta-analysis. Neurosci Biobehav Rev. 2011;35(3):573-588.

40. Kim HS, Shin NY, Jang JH, et al. Social cognition and neurocognition as predictors of conversion to psychosis in individuals at ultra-high risk. Schizophr Res. 2011;130(1-3):170-175.

41. Maher BA. Anomalous experience and delusional thinking: the logic of explanations. In: Oltmanns TF, Maher BA, editors. Delusional Beliefs. New York, NY, USA: Wiley; 1988.

42. Garety PA, Freeman D. Cognitive approaches to delusions: a critical review of theories and evidence. Br J Clin Psychol. 1999;38 Pt 2: 113-154.

43. Bentall RP, Kinderman P, Kaney S. The self, attributional processes and abnormal beliefs: towards a model of persecutory delusions. Behav Res Ther. 1994;32(3):331-341.

44. McKay R, Langdon R, Coltheart M. Jumping to delusions? Paranoia, probabilistic reasoning, and need for closure. Cogn Neuropsychiatry. 2007;12(4):362-376.

45. Bora E, Yucel M, Pantelis C. Theory of mind impairment in schizophrenia: meta-analysis. Schizophr Res. 2009;109(1-3):1-9

46. Balzan RP, Delfabbro PH, Galletly CA, Woodward TS. Illusory correlations and control across the psychosis continuum: the contribution of hypersalient evidence-hypothesis matches. J Nerv Ment Dis. 2013;201(4):319-327.

47. Keefe RSE, Silva SG, Perkins DO, Lieberman JA. The effects of atypical antipsychotic drugs on neurocognitive impairment in schizophrenia: a review and meta-analysis. Schizophr Bull. 1999;25(2):201-222.

48. Keefe RS, Bilder RM, Davis SM, et al; CATIE Investigators; Neurocognitive Working Group. Neurocognitive effects of antipsychotic medications in patients with chronic schizophrenia in the CATIE trial. Arch Gen Psychiatry. 2007;64:633-647.

49. Szöke A, Trandafir A, Longitudinal studies of cognition in schizophrenia: meta-analysis. Br J Psychiatry. 2008;192(4):248-257.

50. Goldberg TE, Goldman RS, Burdick KE, et al. Cognitive improvement after treatment with second-generation antipsychotic medications in first-episode schizophrenia: is it a practice effect? Arch Gen Psychiatry. 2007;64(10):1115-1122.

51. Galletly CA, Clark R, McFarlane AC. Clozapine improves working memory updating in schizophrenia. Eur Neuropsychopharmacol. 2005;15(6):601-608.

52. Sood P, Idris NF, Cole S, Grayson B, Neill JC, Young AM. PD168077, a $\mathrm{D}(4)$ receptor agonist, reverses object recognition deficits in rats: potential role for $\mathrm{D}(4)$ receptor mechanisms in improving cognitive dysfunction in schizophrenia. J Psychopharmacol. 2011;25(6):792-800.

53. Corrigan MH, Gallen CC, Bonura ML, Merchant KM; Sonepiprazole Study Group. Effectiveness of the selective D4 antagonist sonepiprazole in schizophrenia: a placebo-controlled trial. Biol Psychiatry. 2004;55(5): $445-451$.

54. Thakurathi N, Vincenzi B, Henderson DC. Assessing the prospect of donepezil in improving cognitive impairment in patients with schizophrenia. Expert Opin Investig Drugs. 2013;22(2):259-265. 
55. Chouinard S, Stip E, Poulin J, et al. Rivastigmine treatment as an add-on to antipsychotics in patients with schizophrenia and cognitive deficits. Curr Med Res Opin. 2007;23(3):575-583.

56. Lindenmayer JP, Khan A. Galantamine augmentation of longacting injectable risperidone for cognitive impairments in chronic schizophrenia. Schizophr Res. 2011;125(2-3):267-277.

57. Ribeiz SR, Bassitt DP, Arrais JA, Avila R, Steffens DC, Bottino CM. Cholinesterase inhibitors as adjunctive therapy in patients with schizophrenia and schizoaffective disorder: a review and meta-analysis of the literature. CNS Drugs. 2010;24(4):303-317.

58. Singh J, Kour K, Jayaram MB. Acetylcholinesterase inhibitors for schizophrenia. Cochrane Database Syst Rev. 2012;1:CD007967.

59. de Leon J, Diaz FJ. A meta-analysis of worldwide studies demonstrates an association between schizophrenia and tobacco smoking behaviors. Schizophr Res. 2005;76(2-3):135-157.

60. Chen XS, Li CB, Smith RC, Xiao ZP, Wang JJ. Differential sensory gating functions between smokers and non-smokers among drug-naive first episode schizophrenic patients. Psychiatry Res. 2011;188(3): $327-333$.

61. Freedman R, Coon H, Myles-Worsley M, et al. Linkage of a neurophysiological deficit in schizophrenia to a chromosome 15 locus. Proc Natl Acad Sci U S A. 1997;94(2):587-592.

62. Morisano D, Wing VC, Sacco KA, Arenovich T, George TP. Effects of tobacco smoking on neuropsychological function in schizophrenia in comparison to other psychiatric disorders and non-psychiatric controls. Am J Addict. 2013;22(1):46-53.

63. Young JW, Geyer MA. Evaluating the role of the alpha-7 nicotinic acetylcholine receptor in the pathophysiology and treatment of schizophrenia. Biochem Pharmacol. 2013;86(8):1122-1132.

64. Levin ED, Rezvani AH. Development of nicotinic drug therapy for cognitive disorders. Eur J Pharmacol. 2000;393(1-3):141-146.

65. Smith RC, Warner-Cohen J, Matute M, et al. Effects of nicotine nasal spray on cognitive function in schizophrenia. Neuropsychopharmacology. 2006;31(3):637-643.

66. Warburton DM, Rusted JM, Fowler J. A comparison of the attentional and consolidation hypotheses for the facilitation of memory by nicotine. Psychopharmacology (Berl). 1992;108(4):443-447.

67. Barr RS, Culhane MA, Jubelt LE, et al. The effects of transdermal nicotine on cognition in nonsmokers with schizophrenia and nonpsychiatric controls. Neuropsychopharmacology. 2008;33(3):480-490.

68. Freedman R, Olincy A, Buchanan RW, et al. Initial phase 2 trial of a nicotinic agonist in schizophrenia. Am J Psychiatry. 2008;165(8): 1040-1047.

69. Wittkampf LC, Arends J, Timmerman L, Lancel M. A review of modafinil and armodafinil as add-on therapy in antipsychotic-treated patients with schizophrenia. Ther Adv Psychopharmacol. 2012;2(3):115-125.

70. Wing VC, Wass CE, Bacher I, Rabin RA, George TP. Varenicline modulates spatial working memory deficits in smokers with schizophrenia. Schizophr Res. 2013;149(1-3):190-191.

71. Lohr JB, Liu L, Caligiuri MP, et al. Modafinil improves antipsychoticinduced parkinsonism but not excessive daytime sleepiness, psychiatric symptoms or cognition in schizophrenia and schizoaffective disorder: a randomized, double-blind, placebo-controlled study. Schizophr Res. 2013;150(1):289-296.

72. Blasi G, Napolitano F, Ursini G, et al. Association of GSK-3 $\beta$ genetic variation with GSK-3 $\beta$ expression, prefrontal cortical thickness, prefrontal physiology, and schizophrenia. Am J Psychiatry. 2013;170(8):868-876.

73. King MK, Pardo M, Cheng Y, Downey K, Jope RS, Beurel E. Glycogen synthase kinase-3 inhibitors: rescuers of cognitive impairments. Pharmacol Ther. 2014;141(1):1-12.

74. Chan MH, Chiu PH, Lin CY, Chen HH. Inhibition of glycogen synthase kinase-3 attenuates psychotomimetic effects of ketamine. Schizophr Res. 2012;136(1-3):96-103.

75. de Bartolomeis A, Sarappa C, Magara S, Iasevoli F. Targeting glutamate system for novel antipsychotic approaches: relevance for residual psychotic symptoms and treatment resistant schizophrenia. Eur J Pharmacol. 2012;682(1-3):1-11.
76. Lin CY, Tsai GE, Lane HY. Assessing and treating cognitive impairments in schizophrenia: current and future. Curr Pharm Des. January 10, 2014. [Epub ahead of print.]

77. Galletly CA. Recent advances in treating cognitive impairment in schizophrenia. Psychopharmacology. 2009;202(1-3):259-273.

78. Dark F, Cairns A, Harris A. Cognitive remediation: the foundation of psychosocial treatment of schizophrenia. Aust $N Z J$ Psychiatry. 2013;47(6):505-507.

79. Harvey K, Galletly C, Proeve M, Field C. The effects of verbalisation on cognitive performance in schizophrenia: a pilot study using tasks from the Delis Kaplan executive function system. Neuropsychol Rehabil. 2009;19(5):733-741.

80. McGurk SR, Mueser KT, Pascaris A. Cognitive training and supported employment for persons with severe mental illness: one-year results from a randomized controlled trial. Schizophr Bull. 2005;31(4): 898-909.

81. Royer A, Grosselin A, Bellot C, et al. Is there any impact of cognitive remediation on an ecological test in schizophrenia? Cogn Neuropsychiatry. 2012;17(1):19-35.

82. Bowie CR, McGurk SR, Mausbach B, Patterson TL, Harvey PD. Combined cognitive remediation and functional skills training for schizophrenia: effects on cognition, functional competence, and realworld behavior. Am J Psychiatry. 2012;169(7):710-718.

83. McGurk SR, Twamley EW, Sitzer DI, McHugo GJ, Mueser KT. A metaanalysis of cognitive remediation in schizophrenia. Am J Psychiatry. 2007;164(12):1791-1802.

84. Wykes T, Reeder C, Landau S, et al. Cognitive remediation therapy in schizophrenia: randomised control trial. Br J Psychiatry. 2007;190(5): $421-427$.

85. Wykes T. Cognitive remediation therapy needs funding. Nature. 2010;468(7321):165-166.

86. Velligan DI, Diamond PM, Maples NJ, et al. Comparing the efficacy of interventions that use environmental supports to improve outcomes in patients with schizophrenia. Schizophr Res. 2008;102(1-3): 312-319.

87. Statucka M, Walder DJ. Efficacy of social cognition remediation programs targeting facial affect recognition deficits in schizophrenia: a review and consideration of high-risk samples and sex differences. Psychiatry Res. 2013;206(2-3):125-139.

88. Sacks S, Fisher M, Garrett C, et al. Combining computerized social cognitive training with neuroplasticity-based auditory training in schizophrenia. Clin Schizophr Relat Psychoses. 2013;7(2): $78 \mathrm{~A}-86 \mathrm{~A}$

89. Hogarty GE, Flesher S, Ulrich R, et al. Cognitive enhancement therapy for schizophrenia: effects of a 2-year randomized trial on cognition and behavior. Arch Gen Psychiatry. 2004;61(9):866-876.

90. Moritz S, Woodward TS. Metacognitive training in schizophrenia: from basic research to knowledge translation and intervention. Curr Opin Psychiatry. 2007;20(6):619-625.

91. Aghotor J, Pfueller U, Moritz S, Weisbrod M, Roesch-Ely D. Metacognitive training for patients with schizophrenia (MCT): Feasibility and preliminary evidence for its efficacy. J Behav Ther Exp Psychiatry. 2010;41(3):207-211.

92. Rajji TK, Rogasch NC, Daskalakis ZJ, Fitzgerald PB. Neuroplasticitybased brain stimulation interventions in the study and treatment of schizophrenia: a review. Can J Psychiatry. 2013;58(2):93-98.

93. Voineskos D, Daskalakis ZJ. A primer on the treatment of schizophrenia through repetitive transcranial magnetic stimulation. Expert Rev Neurother. 2013;13(10):1079-1082.

94. Aleman A, Sommer IE, Kahn RS. Efficacy of slow repetitive transcranial magnetic stimulation in the treatment of resistant auditory hallucinations in schizophrenia: a meta-analysis. J Clin Psychiatry. 2007;68(3): 416-421.

95. Slotema CW, Blom JD, Hoek HW, et al. Should we expand the toolbox of psychiatric treatment methods to include repetitive transcranial magnetic stimulation (rTMS)? A meta-analysis of the efficacy of rTMS in psychiatric disorders. J Clin Pscyhiatry. 2010;71(7):873-884. 
96. Sachdev P, Loo C, Mitchell P, et al. Transcranial magnetic stimulation for the deficit syndrome of schizophrenia: a pilot investigation. Psychiatry Clin Neurosci. 2005;59(3):354-357.

97. Jin Y, Potkin SG, Kemp AS, et al. Alpha EEG guided TMS in schizophrenia. Brain Stimul. 2012;5(4):560-568.

98. Prikryl R, Kasparek T, Skotakova S, et al. Treatment of negative symptoms of schizophrenia using repetitive transcranial magnetic stimulation in a double-blind, randomized controlled study. Schizophr Res. 2007;95(1-3):151-157.

99. Levkovitz Y, Rabany L, Harel EV, Zangen A. Deep transcranial magnetic stimulation add-on for treatment of negative symptoms and cognitive deficits of schizophrenia: a feasibility study. Int $J$ Neuropsychopharmacol. 2011;14(7):991-996.
100. Ditye T, Jacobson L, Walsh V, Lavidor M. Modulating behavioral inhibition by tDCS combined with cognitive training. Exp Brain Res. 2012;219(3):363-368

101. Wing VC, Bacher I, Wu BS, Daskalakis ZJ, George TP. High frequency repetitive transcranial magnetic stimulation reduces tobacco craving in schizophrenia. Schizophr Res. 2012;139(1-3):264-266.

102. National Institute for Health and Care Excellence. NICE clinical guidelines. Available at: http://guidance.nice.org.uk/CG/Published. Accessed March 4, 2014.

Neuroscience and Neuroeconomics

\section{Publish your work in this journal}

Neuroscience and Neuroeconomics is an international, peer-reviewed, open access journal focusing on the identification of brain structures and measurement of neural activity related to behavior, behavioral predictions, and decision making in health and disease. The manuscrip management system is completely online and includes a very quick and fair peer-review system. Visit http://www.dovepress.com/testimonials. php to read real quotes from published authors. 